\title{
Morphological operation method for eggs identification in gonad ultrasound image for Mahseer's fish (Tor tombroides)
}

\begin{abstract}
This paper describes an approach based on morphological operation for identifying the eggs in Mahseerôs gonad ultrasound image. In the context of breeding and seed production of Mahseer species, understanding and control of the Mahseer gonad maturation level have given strong interest for scientific and commercial purposes. From the studies, this Mahseerôs fish have different stage and size of eggs at the same time. Therefore, to identify the eggs in the gonad ultrasound image, an appropriate method is required. Morphological operation dilation and erosion with the structuring element shape is applied in this paper. In between these two operators, morphological reconstruction that includes filling the hole and clearing the border are also applied to the image. This method is essential for eliminating the egg sac because only the eggs region in the gonad will be processed. The proposed method also have been compared with the other research paper method. The result shows that the proposed method effectively identify the eggs in the gonad ultrasound image compared with the other research paper method. To our knowledge, this is the first report on the use of the morphological operation method in the gonad ultrasound image of Mahseerôs fish.
\end{abstract}

Keyword: Dilation; Erosion; Mahseer; Morphological operation; Morphological reconstruction; Ultrasound 